\title{
Las estrategias empresariales del agronegocio en la era de la financiarización. El caso de El Tejar
}

\section{Andrea Patricia Sosa Varrotti \\ Universidad Nacional de San Martín, Argentina andreapatriciasosa@gmail.com}

\section{Samuel Frederico}

Universidade Estadual Paulista "Júlio de Mesquita Filho", Brasil samuelfrederico7@gmail.com

Cita sugerida: Sosa Varrotti, A. y Frederico, S. (2018). Las estrategias empresariales del agronegocio en la era de la financiarización. El caso de El Tejar. Mundo Agrario, 19(41), e086. https://doi.org/10.24215/15155994e086

Recibido: 1 de enero 2018 - Aceptado: 8 de agosto 2018 - Publicado: 15 de Agosto 2018

(c) (i) (s) Esta obra está bajo licencia Creative Commons Atribución-NoComercial-CompartirIgual 4.0 Internacional

cc. $h$ ittp://creativecommons.org/licenses/by-nc-sa/4.0/deed.es_AR 


\section{Las estrategias empresariales del agronegocio en la era de la financiarización. El caso} de El Tejar

Agribusiness Entrepreneurial Strategies during Financialization Era. A Case Study: El Tejar

Andrea Patricia Sosa Varrotti

Universidad Nacional de San Martín, Argentina

andreapatriciasosa@gmail.com

Samuel Frederico

Universidade Estadual Paulista "Júlio de Mesquita Filho", Brasil

samuelfrederico7@gmail.com

\section{RESUMEN:}

En este artículo analizamos un aspecto central de la financiarización de la agricultura del Mercosur: el ingreso de capitales de riesgo en el sector. Entre los protagonistas de este proceso se encuentran las firmas de private equity y las megaempresas del agronegocio en las cuales invierten. Gracias a un abordaje cualitativo-cuantitativo, analizamos uno de los ejemplos más acabados de vínculo entre ambos tipos de empresa a partir de un estudio de caso, la megaempresa de origen argentino El Tejar, y sus efectos en términos de acaparamiento de tierras y de la producción en Argentina y Brasil.

Palabras ClaVE: Financiarización, Agronegocio, Megaempresas, Acaparamiento, Mercosur, Brasil, Argentina, Tierras.

\section{Abstract:}

In this article, we analyze a central aspect of Mercosur's agriculture financialization: the entrance of risk capital in this economic sector. Among the main actors in this process, we can find private equity firms and the agribusiness mega-companies on which they invest. Using a qualitative-quantitative approach, we analyze one of the most accomplished examples of relationship between both types of companies thought a case study, the mega-company El Tejar -of Argentinean origin-, and its effects in terms of land and production grabbing in Argentina and Brazil.

KeYwORDs: Financialization, Agribusiness, Mega-companies, Grabs, Mercosur, Brazil, Argentina, Lands.

\section{INTRODUCCIÓN}

Este artículo analiza el proceso de financiarización de la agricultura y sus consecuencias materiales en términos de la profundización de los procesos seculares de concentración en los países del Mercosur (Argentina, Bolivia, Brasil, Paraguay, Uruguay). Lo hace a través del análisis de actores poco estudiados en su relación con estos procesos: las megaempresas de producción agropecuaria de origen argentino.

Entre los agentes de la expansión financiera reciente en la agricultura, producida por la desregulación de la economía mundial, tanto grandes supermercados y agentes financieros (Burch y Lawrence, 2005, 2009) como las corporaciones multinacionales del agronegocio (Goldfarb, 2013; Wesz Junior, 2014) fueron analizados en su papel de actores centrales de este proceso. No obstante, el papel de las megaempresas de producción agropecuaria - principales aliadas de estas corporaciones y de los agentes financieros- no ha sido abordado, a no ser por algunas excepciones (Bernardes, Frederico, Gras, Hernández, y Maldonado, 2017; Sosa, 2017). En línea con estos últimos estudios se inscribe este trabajo.

Aquí sostenemos que el carácter financiero que imprimen estas empresas a la actividad agrícola da cuenta del proceso de financiarización de la agricultura, hecho que escapa a estudios anteriores sobre estos actores, que se focalizan en su actividad productiva (Artopoulos, 2015; Bell y Scott, 2010; Nichols y Ordoñez, 2003).

Es decir que, por un lado, el interés por las megaempresas se debe a que representaron un vehículo privilegiado de inversiones especulativas, no solo de origen nacional, sino también internacional, al tiempo que introdujeron nuevas prácticas financieras en el sector. 
Por otro lado, responde a la necesidad de comprender el papel de las elites locales y de las empresas que controlan en el fenómeno de acaparamiento de tierras (land grabbing) en América Latina, señalado pero no suficientemente analizado por algunos autores (Wolford, Borras, Hall, Scoones, y White, 2013), ni por otros trabajos sobre las megaempresas (Moreno, 2017; Toledo López, 2017).

En la primera parte de este artículo se presenta la expansión financiera reciente en el sector agropecuario como un aspecto de la financiarización de la economía. Se hace hincapié en lo que puede llamarse financiarización directa, es decir, el ingreso de capitales especulativos en la llamada "economía real" (por oposición a la financiarización inversa, que implica la adopción de prácticas financieras por parte de actores considerados productivos). Por esta razón, se resalta el papel central que adquieren los fondos de private equity en el capitalismo contemporáneo, y su creciente participación en el sector agropecuario y en el mercado de tierras desde comienzos del siglo XXI, lograda entre otros modos a través de inversiones en las megaempresas estudiadas. El término private equity hace referencia a inversiones en empresas privadas no listadas en las bolsas de valores.

Luego, se presenta el caso de estudio, El Tejar. Este caso fue elegido porque representa un ejemplo paradigmático de megaempresa que participa del proceso de financiarización directa - primero a través del formato del pool de siembra y luego debido al ingreso de capitales financieros internacionales en su estructura accionaria-, así como de sus consecuencias en términos de acaparamiento.

El trabajo de campo consistió en la realización de entrevistas (semiestructuradas y en profundidad) a 31 personas vinculadas a esta empresa, así como de observaciones no participantes en las sedes de la empresa en Saladillo (Provincia de Buenos Aires, Argentina) y Primavera do Leste (Mato Grosso, Brasil) entre 2012 y 2015. A estas técnicas cualitativas se le sumó el análisis de documentos de y sobre la empresa.

Esto permitió distinguir tres períodos en la trayectoria empresarial de El Tejar, que echan luz sobre los procesos de financiarización y acaparamiento: 1) fundación y expansión nacional, cuando se arma su "modelo en red"; 2) expansión translatina y, en particular, despliegue territorial en Brasil, y los alcances del "trasplante" (Boyer, 1998) de ese modelo de negocios; y 3) la salida de la inversión.

La empresa El Tejar S. A. fue fundada en Argentina en 1987, y durante dos décadas mantuvo el carácter familiar de su capital y patrimonio. Este rasgo se vio alterado en 2006, cuando acudió a capitales especulativos internacionales (la mayoría, firmas de tipo private equity) para potenciar un proceso incipiente de expansión transfronteras, lo que la convirtió en un caso analítico privilegiado del proceso de financiarización directa de la agricultura.

En 2009, El Tejar llegó a sembrar casi un millón de hectáreas en los países del Mercosur; es decir que la trayectoria de esta empresa también permite analizar el proceso global de acaparamiento de tierras. Sin embargo, hacia 2012, El Tejar emprendió un proceso de reestructuración, que implicó la venta de operaciones en varios países, para concentrarse en Brasil.

Focalizamos nuestra atención en las dos últimas etapas (expansión translatina y salida de la inversión), ya que es cuando se evidencia con mayor claridad el proceso de financiarización directa, así como algunas de sus consecuencias. Además, reflexionamos sobre los problemas que El Tejar tuvo que afrontar en territorio brasilero para extender el modelo de negocios creado en Argentina. Por último, analizamos el papel que desempeña el capital financiero, en su alianza con empresas agropecuarias, sobre el proceso de acaparamiento de tierras y de la producción. Este objeto de estudio exige una perspectiva multiescalar que incorpore fenómenos globales en el análisis de dinámicas territorialmente circunscriptas a los diferentes países de la región.

\section{Financiarización DE LA AgRiCUlTURA: EL PAPEL DE LAS FIRMAS DE PRIVATE EQUiTY}

Desde la década de 1970, las expansiones financieras posibilitadas por la desregulación de los mercados implicaron una mayor incidencia de agentes especulativos en la llamada "economía real": consorcios de 
private equity, fondos de cobertura de riesgo (hegde funds), gestores de fondos de inversión, fondos de pensión, bancos comerciales, fondos soberanos, entre otros (Lawrence, Sippel y Burch, 2015).

La aparición de agentes financieros en actividades productivas que anteriormente no revestían interés como destino de inversiones especulativas es, de este modo, uno de los indicadores principales de la financiarización de la economía. Este proceso consiste en que el capital financiero cobra preeminencia sobre otras fracciones del capital y altera el funcionamiento económico general (Chesnais, 1996). Ello implica un aumento del llamado "poder accionarial" (Aglietta y Rebérioux, 2004; Chesnais, 2004; Plihon, 2009), al tiempo que el capital productivo se acerca en sus intereses al capital financiero (Epstein, 2001, p. 17).

La agricultura comenzó a ser especialmente atractiva para estos agentes a comienzos del siglo XXI, luego de la explosión de la burbuja financiera generada por la inversión especulativa en empresas dedicadas a las nuevas tecnologías (Clarke, 2015; Honan y Leckart, 2010; Pierrakis, 2010). Este interés estuvo vinculado al boom del precio de los commodities entre 2003 y 2008, año en que se vio renovado por la crisis desencadenada con la explosión de una nueva burbuja, esta vez producto de la especulación inmobiliaria (Altman, 2009; Sassen, 2010).

Es decir que, desde 2000-2002, y en especial a partir de 2008, la producción de commodities (Masters, 2008) y la especulación inmobiliaria con tierras (Fairbairn, 2014) se encuentran entre los principales nuevos destinos de estos capitales, hasta entonces reticentes a la inmovilización de capital en activos con poca liquidez como plantaciones o haciendas. Fue en esos años que los capitales de riesgo internacionales comenzaron a invertir en las megaempresas de origen argentino estudiadas.

Una de las novedosas estrategias adoptadas por el capital financiero para insertarse en la producción agrícola fue la creación de los fondos de private equity. Las firmas que gestionan estos fondos se especializan en la adquisición de acciones de empresas con gran potencial de crecimiento a corto o mediano plazo, elevación de su precio de mercado y posterior venta de las empresas adquiridas.

Cuando las adquisiciones accionarias son de tipo mayoritario (lo que les otorga control en el directorio de la empresa), adoptan medidas de reestructuración para disminuir costos, aumentar la productividad, y así hacer crecer su precio de mercado. Para esto, a veces recurren a la toma de crédito o "apalancamiento" (tipo de endeudamiento cuyo objetivo es aumentar la rentabilidad financiera que se deriva de la disminución del capital inicial invertido), aunque a veces ello comprometa la salud financiera a largo plazo de la empresa adquirida (Singh, 2008).

Es importante resaltar que los capitales de riesgo en general (venture capital, hedge funds, private equity, entre otros)identifican en la salida de la inversión (exit) la fuente principal de su ganancia financiera en relación con el capital invertido. Sin embargo, son en particular las firmas de private equity las que se especializan en generar estrategias exitosas de exit, siendo la más anhelada la apertura de capital o IPO (Initial Public Offering) en las bolsas de valores del mundo.

Otras estrategias son la venta de acciones -o incluso de toda la operación- a "compradores estratégicos" a través de adquisiciones accionarias (divestiture), o la venta de activos a través de una "desinversión" más o menos progresiva en el sentido de "reducir la inversión en bienes de capital, vendiéndolos o no reemplazándolos cuando finaliza su vida útil" (disinvestment) (Nasdaq, 2017). Esta última opción "implica la reducción de la capacidad productiva (...) sin salir del negocio de una vez" (Sull, 2005, p. 135).

Asimismo, todo puede terminar en un simple fracaso de la operación (Cochrane, 2005). Sea cual fuere el mecanismo, el momento del exit o salida de la inversión es tan importante en la lógica de los capitales de riesgo que resulta un indicador de la performance de la inversión (Nanda, Samila, y Sorenson, 2017).

Haciéndose eco de un discurso neomaltusiano según el cual la creciente demanda de alimentos y de energía (biocombustibles) a nivel mundial hace de estas "inversiones alternativas" en agricultura una forma segura de reproducir el capital que manejan, estas firmas comenzaron a adquirir acciones a lo largo de toda la cadena agrícola: desde la producción de insumos como semillas o agroquímicos, pasando por la producción propiamente dicha, hasta el procesamiento y la comercialización de granos. Además, comenzaron a comprar 
grandes cantidades de tierras con fines especulativos y productivos, en especial en Asia, África y América Latina, participando así del fenómeno de acaparamiento de tierras o land grabbing.

Es decir que la expansión financiera en el agro, en especial cuando se trata de inversiones en tierras y en actividades productivas, parece responder al agotamiento de los canales puramente financieros de acumulación en un contexto postcrisis, y a "un deseo, aunque más no fuera parcial e incluso temporal, de volver a la economía real” por parte de los inversores (Fairbairn, 2014, p. 8; la traducción es propia).

En 2008, la caída de las bolsas de valores terminó de convertir a la tierra en un "activo financiero" alternativo, impulsando una suerte de "fiebre" por tierras y por los llamados "recursos naturales" (Cotula, 2012). La "fiebre" por tierras o "global land rush", consiste en el acelerado aumento en las transacciones de tierras en buena parte del mundo. La bibliografía identifica el conjunto de estos procesos como land grabbing, production grabbingy green grabbing, respectivamente (GRAIN, 2008; Borras Jr., Kay, Gómez, y Wilkinson, 2012; Cotula, 2012; McMichael, 2012).

Es decir que la expansión financiera es un "fenómeno profundamente espacio-temporal" (French, Leyshon, y Wainwright, 2011, p. 800). Los efectos de las estrategias especulativas en la concentración de tierras se encuentran estrechamente relacionados con la puesta en producción de tierras en áreas de frontera bajo el modelo del agronegocio (agribusiness) (Sauer, 2010). Más aún, la financiarización está directamente vinculada al acaparamiento de tierras y de la producción (Ducastel y Anseeuw, 2011).

Según el informe Private Equity and Emerging Markets Agribusiness, entre 2008 y 2014, en el sector agrícola, el promedio anual de inversiones de capital privado se elevó a mil millones anuales distribuidos en 30 negociaciones por año. El $76 \%$ de estas inversiones fueron dedicadas a la adquisición del control de empresas agropecuarias (incluyendo la compra de tierras), el $15 \%$ para la adquisición de empresas de agroquímicos, $6 \%$ de empresas forestales y la industria de papel y celulosa, $2 \%$ para tradings (exportadoras de productosagrícolas), y $1 \%$ a la agroindustria en general. En particular, Brasil recibió alrededor del $80 \%$ de las inversiones de estos fondos en América Latina (EMPEA, 2015). Debe aclararse que ese informe no es exhaustivo, pero da cuenta de por qué se llama "nuevos reyes del capitalismo" (The Economist, 2004) a estos fondos.

En el siguiente apartado veremos cuáles son algunas de las empresas en las que invierten estos nuevos reyes: las megaempresas de origen argentino. Luego, se estudiará el caso de El Tejar que, al haberse expandido en Brasil, representa un ejemplo característico de estas inversiones de tipo private equity y del proceso de acaparamiento de tierras y de la producción que promueven estos fondos.

\section{El PAPEL de laS MEgaempresas DEL Agronegocio EN LA FiNANCIARIZACIón}

Al hablar de megaempresas aludimos a un conjunto específico de firmas agropecuarias que, tal como señalara Miguel Murmis (1988), se distancian del conjunto de empresas del sector por la magnitud de su volumen y escala de producción. Con el comienzo del siglo, cada una de ellas llegó a controlar mediante diversas combinaciones de formas de acceso a la tierra (básicamente alquiler y compra) más de 200 mil hectáreas en los países que actualmente constituyen el Mercosur: Argentina, Brasil, Uruguay, Paraguay, Bolivia.

Como se explicita en Gras y Sosa Varrotti (2013), estas empresas desarrollaron un modelo empresarial basado en a) grandes escalas productivas; b) organización “en red” de la producción; c) diversificación territorial y de cultivos como formas de manejo de riesgos climáticos, productivos y políticos; d) uso intensivo de tecnologías de la información y la comunicación (TICs) en la actividad productiva y en la organización de la división territorial del trabajo; e) diversas formas de conexión con el capital financiero. Los Grobo, Cresud, MSU, CalixAgro y Adecoagro son algunos de los ejemplos que, como El Tejar, conforman este selecto estrato.

Es decir que estas empresas crearon y perfeccionaron un modelo flexible de organización del trabajo y la producción -denominado por ellas, por la prensa y por trabajos académicos, "modelo en red"-, que consiste, de manera esquemática, en la tercerización de las tareas agrícolas, arrendamiento como forma predominante 
del control de la tierra, leasing de maquinaria y manejo de capital de terceros. A nuestro entender, este modelo facilitó el interés e ingreso de capitales financieros - primero de origen nacional y, más tarde, internacionalen el sector agropecuario de la región, y por ello debe ser estudiado como factor de la expansión financiera en el sector.

El ingreso de capitales especulativos extra-agrarios en la actividad impulsó el despliegue del modelo flexible de organización productiva desarrollado por estas megaempresas en Argentina -con adaptaciones, fracasos y éxitos- a varios países del Mercosur. La dimensión regional adquirida por las megaempresas está estrechamente vinculada al volumen de capital al que tuvieron acceso a partir del ingreso de estos capitales financieros en su estructura. Para el caso de estudio seleccionado, El Tejar S. A., haremos hincapié en los dos principales países de actuación, Argentina y Brasil, si bien también se hará mención a su expansión en Uruguay, Bolivia y Paraguay.

\section{Orígenes, EXPANSión NACIONAL Y ARMADo DEL MODELO DE NEgocios “EN RED” DE EL TeJAR (1987-2003/04)}

La empresa El Tejar surgió de la iniciativa de una familia que manejaba una empresa pecuaria de una pequeña ciudad Saladillo, Provincia de Buenos Aires. Entre 1992 y 1994, Oscar Alvarado (hijo de los fundadores) reunió los fondos de varias familias de la zona a través de un esquema empresarial asociativo con metas de crecimiento altas, lo que incluía desde el inicio la perspectiva de "cotizar en la bolsa" (FISOA, 2012, p. 45). Una de las novedades de esta asociación es que alquilaba los campos a sus propios dueños. Además, tercerizaba en contratistas la realización de trabajos agrícolas, que en ese momento era una actividad menor en el esquema empresarial.

En 1995, la empresa dio un vuelco radical en su estrategia, para comenzar a dedicarse mayormente a la agricultura usando la técnica de la siembra directa. Desde ese momento, El Tejar arrendó parte de las tierras que manejaba en la Cuenca del Salado, donde convirtió tierras ganaderas de baja o nula aptitud agrícola en tierras agrícolas gracias a esa técnica.

En su estatuto inicial, El Tejar dejó asentado que no poseía activos fijos. Esto impidió conseguir créditos formales, principalmente otorgados por bancos públicos y privados. Por eso, El Tejar buscó a sus inversores en los mercados informales de capitales, de manera que fue un importante vehículo, y uno de los primeros, para el ingreso de capitales financieros de origen nacional en el sector agropecuario, en primer lugar, gracias al formato del pool de siembra.

En esos años, los pools de siembra aparecían como una modalidad novedosa de organización de la producción en la región pampeana, y el contrato "accidental" (por dos cosechas) se extendía como forma de acceso a la tierra. En su forma más básica, los pools de siembra son asociaciones formales o informales entre actores que consiguen reunir los factores productivos (tierra, maquinaria, capital) a partir de su vinculación con quienes los poseen, y cuyo propósito es maximizar la inversión realizada en la producción agrícola. Se trata de uno de los principales motores de la la expansión financiera reciente en el sector agropecuario argentino.

El Tejar llegaría a convertirse en un ejemplo paradigmático de pool de siembra, no solo por el tamaño al que llegaría hacia el momento de la salida de la inversión a comienzos de la segunda década de este siglo, sino también porque se especializó en la producción agrícola bajo ese formato. En 1997, El Tejar ya había alcanzado las 10 mil hectáreas sembradas, integrando las tierras de sus socios iniciales, además de las de otros propietarios locales, y sumando una fuente de financiamiento hasta entonces poco frecuente: el aporte de inversores de origen nacional externos a la actividad.

Estas fuentes de capital fueron solo el puntapié inicial de la estrategia de financiamiento de la empresa. Desde los años noventa, su "misión" explícita fue llegar al millón de hectáreas sembradas para "convertirse en la empresa del sector agroindustrial más grande del mundo" (FISOA, 2012, p. 79) y así poder "cotizar en la bolsa" (FISOA, 2012, p. 45). 
Para sortear la competencia con otros pools y crecer a escalas "siderales" (FISOA, 2012, p. 159), llegó a ofrecer por los arrendamientos precios por encima de los vigentes en el mercado. Esta estrategia de precios altos, fuera de mercado, permitió a El Tejar eliminar la competencia e iniciar un sostenido acaparamiento de tierras vía arrendamiento. En Saladillo, por ejemplo, llegó a alquilar los campos de la mitad de los productores del partido.

Por otra parte, con los proveedores de servicios que formaban parte de su "red", El Tejar establecía contratos de corto plazo (promedio de un año) para poner las tierras alquiladas en producción. Al acaparar tierras a través del alquiler a un ritmo acelerado gracias a esta estrategia que puede llamarse de "inflación artificial" de los alquileres, aseguraba grandes cantidades de hectáreas a estos prestadores. Como contrapartida, la empresa decidía el precio que pagaba por los laboreos.

Según señaló la mayoría de los entrevistados, los contratos establecidos entre El Tejar y los prestadores eran formales. Sin embargo, la empresa no informaba claramente a los contratistas cuál sería el monto que finalmente se abonaría por las labores contratadas, ni tampoco cuándo se haría efectivo el pago. Por lo demás, las cargas sociales del personal que trabajaba en las empresas contratistas eran absorbidas por ellas mismas, además de ser responsables por la seguridad de cada trabajador. Como otras empresas de su tipo, El Tejar exigía a sus prestadores que mantuvieran una actualización tecnológica continua; de este modo, transfería los costos de renovación de las maquinarias.

En contraposición a los contratos establecidos con los prestadores de servicios, El Tejar estableció contratos de largo plazo cada vez más sólidos con los grandes proveedores de insumos (semillas y agroquímicos), pero también de maquinaria y transporte. Esto les permitía negociar precios competitivos que estaban fuera del alcance de la mayoría de los productores individuales, e incluso de otras empresas, ventaja que fue potenciándose con el tiempo. Además de las empresas de agroinsumos, también eran consideradas "aliadas estratégicas" las grandes exportadoras.

\section{EXPANSIÓN TRANSLATINA E INGRESO DE CAPITALES ESPECULATIVOS INTERNACIONALES (2003/04-2012/13)}

Gracias al modelo empresarial descrito en el apartado anterior, en pocos años El Tejar logró multiplicar la cantidad de tierras que controlaba en Argentina, y en 2002 hizo una primera incursión en el sur de Bolivia. Pero fue en 2003 cuando se produjo una nueva inversión de empresarios nacionales que le permitió despegar en su proceso de translatinización.

Ese año El Tejar sembró 55 mil hectáreas en Argentina (distribuidas en las provincias de Buenos Aires, Chaco, Corrientes y Entre Ríos); 4 mil hectáreas en Santa Cruz de la Sierra, Bolivia; 8 mil hectáreas en los departamentos de Río Negro y de Paysandú, en Uruguay, y 5 mil hectáreas en el estado de Mato Grosso, Brasil (La Mañana, 2003; citado en El Tejar, 2009, p. 39). Tanto en Bolivia como en Uruguay y Brasil intentaron reproducir el modelo de negocios argentino.

Los resultados iniciales de este proceso de translatinización no fueron los mejores. Con el primer desembarco en Brasil se perdieron 2 millones de dólares, lo que generó un déficit importante para la empresa, ya que no todos los socios asumieron los malos resultados económicos. Esto fue preparando el escenario para una crisis cercana al quebranto cuya resolución cambiaría de manera definitiva el perfil empresarial de El Tejar.

La inexperiencia había llevado a una elección equivocada de suelos y una tecnología poco adecuada y a un esquema asociativo que no era el más acertado (...) De los socios iniciales que superaban la decena, quedaron solo cuatro (...) Estos socios no recuperaron su inversión pero recibieron en cambio acciones de El Tejar y se convirtieron en accionistas (FISOA, 2012, p. $153)$. 
En Uruguay, donde se instaló con el nombre de "Tafilar",la empresa debió enfrentar problemas vinculados con la inexistencia de empresas prestadoras de servicios, uno de los pilares fundamentales del modelo de negocios, y con la "cultura de trabajo" local, en especial, los ritmos de trabajo.

A pesar de estas dificultades, en los años subsiguientes El Tejar insistió con la estrategia y "redobló la apuesta" (FISOA, 2012, p. 151). En la campaña 2004/05 llegó a sembrar 105 mil hectáreas en todo el Mercosur: 77 mil en Argentina, 13 mil en Brasil, 13 mil en Uruguay, y 5 mil hectáreas en Bolivia (Palermo, 2004; citado en El Tejar, 2009, p. 47).

En todos estos países, El Tejar buscó inicialmente trasplantar el modelo de negocios “en red". Para ello, debió organizar empresas contratistas, que no existían en ninguno de esos países, siendo la de Uruguay la experiencia más exitosa. Otra estrategia utilizada para saldar el problema de la ausencia de prestadores de servicios fue la de ofrecer a algunos contratistas argentinos trabajo en varios países, por lo que debieron especializarse en las tareas que El Tejar les asignaba.

La diversificación regional le dio visibilidad internacional a una empresa que hasta entonces solo había tenido una inserción nacional. Resultaban atrayentes sus posibilidades de manejo de riesgos de distinto tipo, como los vinculados a condiciones climáticas y agroecológicas (en especial, gracias a su diversificación territorial y de cultivos), además de su escalabilidad (capacidad para crecer con rapidez). Por lo demás, El Tejar prometía un retorno sobre el capital extremadamente alto, del 30 \% (FISOA, 2012, p. 162).

Finalmente, el modelo de negocios flexible y escalable a nivel regional atrajo al hegde fund Altima Partners LLP. Con su base principal en Londres y sucursales en Nueva York y Mónaco, desde 2004 Altima gerenciaba fondos financieros, en manos de exsocios del Equity Special Situations Group, uno de los fondos de inversión del Deutsche Bank. Según la propia empresa, controlaba en 2017 US\$ 400 millones (Altima Partners, 2017).

Para lograr que este fondo invirtiera, El Tejar debió modificar su estatuto, abandonar su estrategia de cero activos fijos, y disponerse a comprar tierras. La tendencia mundial de aumento del precio de las tierras era uno de los principales alicientes para estos agentes financieros.

La inversión de Altima fue el primer paso de El Tejar en su vinculación con inversores institucionales. Especialista en la creación y la gestión de fondos de private equity, Altima lanzó un fondo de este tipo llamado Altima Global Special Situations Fund (AGSS), con el que adquirió alrededor de un 20\% de las acciones de El Tejar. Según diversas fuentes, esta primera inversión fue de alrededor de US\$ 50 millones (El Cronista, 2009; Oyhantçabal y Narbondo, 2011, p. 54).

Desde esta primera "ronda de inversión” de Altima, El Tejar comenzó a comprar tierras y a producir en ellas a través de un esquema own-operate, según la clasificación realizada por Madeleine Fairbairn (2014) de los actores que participan de la actual "fiebre" por tierras. Según este esquema, el inversor compra tierras y se involucra en su explotación, por lo que corre con los riesgos asociados a la actividad productiva, pero también puede lograr mayores retornos como resultado de esta actividad.

Sin embargo, pese a haber adquirido tierras, El Tejar seguía operando mayormente a través del esquema de arrendamientos. Con el lanzamiento de AGSS, Altima y El Tejar se proponían captar unos US\$ 200 millones. La intención era capitalizar El Tejar para comprar campos en el Mercosur, en especial en Brasil. Para ello, crearon Campos Verdes Ltd., cuya sede radicaron en Bermudas.

Campos Verdes, a través de una compleja trama de sociedades anónimas con base en diferentes países, se convirtió en la dueña de las tierras, y El Tejar se hacía cargo de ponerlas en producción, lo que en la clasificación mencionada correspondería formalmente al esquema own-lease out (en el que el inversor compra tierras para arrendarlas a terceros) descrito por Fairbairn (2014). Campos Verdes era controlada por El Tejar y por los fondos creados por Altima. El más relevante de ellos fue Altima One World Agriculture Fund (AOWAF), creado en 2007 para invertir en la compra de tierras en África subsahariana, América del Sur, y otros mercados "emergentes".

A través de esta red financiera, Altima pasó a controlar campos en Argentina, Brasil, Bolivia y Uruguay. "El negocio que les ofrece a los inversores es valorizar su capital a través del aumento del precio de 
la tierra y, mientras tanto, obtener los beneficios que arroja la producción que se realiza en las tierras compradas" (Caligaris, 2017, p. 482).

Sin embargo, esta arquitectura financiera no fue exitosa: Campos Verdes no logró reunir los montos de capital proyectados y terminó fusionándose con El Tejar a fines de 2007, que mudó su sede a Bermudas bajo el nombre de El Tejar Ltd. (Bloomberg, 2017; Caligaris, 2017, p. 482).

Desde entonces, El Tejar empezó a integrar a distintos tipos de inversores institucionales, colocando títulos en la Bolsa. La empresa "consiguió levantar, en diversos momentos, casi mil millones de dólares, en un primer momento 700 millones de dólares" (Entrevista a alto directivo de El Tejar, 2014).

Además de Altima, otros fondos más pequeños comenzaron a invertir en la empresa. Sur Capital Partners (SCP) fue el primero de ellos. La sede de este fondo de private equity SCP está en Argentina y se especializa en inversiones en Latinoamérica, en particular en ese país y en Chile. Para su director, "Alvarado fue el primer empresario agropecuario capaz de explicarle [a un inversor] el negocio agrícola desde la perspectiva financiera", ya que "aprendió como nadie las virtudes del apalancamiento financiero" (FISOA, 2012, p. 85).

Hacia julio de 2008, El Tejar Ltd. recibió un préstamo de US\$ 150 millones de The Netherlands Development Finance Company (FMO) (El Cronista, 2009), un banco que depende del Banco Central Holandés y que, entre otras actividades, invierte en compañías de tipo private equity en "países en desarrollo" (Revolvy, 2017).

Poco más tarde ingresó otra inversión equivalente de uno de los principales gestores de inversiones de riesgo del mundo, Capital Group, que reúne inversores provenientes principalmente de Estados Unidos y de Europa, por US\$ 1,4 mil millones. Gracias a ambas inversiones, El Tejar sembró más de 900 mil hectáreas en Argentina, Brasil, Bolivia y Paraguay, de las cuales 170 mil eran propias (Caligaris, 2017, p. 483).

En esta etapa translatina se hizo hincapié en fortalecer las estrategias de control del riesgo de la empresa, dado su rápido crecimiento, para lo que se implementaron herramientas como los Análisis de Dominio Orientado a las Características (FODA, por sus siglas en inglés). El desarrollo de este tipo de estrategias suele ser una exigencia de los inversores institucionales. Luego, los inversores también exigirían modificaciones sustanciales del modelo de negocios de El Tejar, con el objetivo de reducir costos para que la empresa fuera atractiva en las bolsas de valores, cuestión que será tratada en el siguiente apartado.

\section{Desempeño EN Brasil: LA "REVANCHA DEL TERritorio"}

El territorio brasilero era estratégico para los inversores institucionales por las posibilidades de expansión de su frontera agrícola (en gran medida agotadas en Argentina) y, por lo tanto, de incorporación de grandes cantidades de tierra barata a la producción de commodities. En 2011/12, Brasil se había convertido en el principal país de actuación, ya que allí controlaba 350 mil hectáreas, de las cuales 250 mil eran propias. Sin embargo, en este país El Tejar registró pérdidas desde los comienzos de su expansión translatina.

En opinión de varios entrevistados, la expansión fue "desprolija” por querer “crecer a cualquier costo", frase que refleja el alto riesgo tomado para incrementar la escala productiva y mantener e incrementar la captación de inversores. En Mato Grosso, región del Cerrado brasilero, El Tejar fue adquiriendo o arrendando campos de mala calidad, arenosos y en zonas marginales, a un precio demasiado alto. Como en Argentina, utilizó la estrategia de la inflación artificial, ofreciendo precios por encima de la media por el arrendamiento de las tierras. Según el relato de los propios productores durante entrevistas realizadas en el Municipio de Sorriso, Mato Grosso, mientras que el costo del arrendamiento giraba entre las 10 y las 12 bolsas de soja por hectárea, El Tejar ofrecía 15 bolsas.

También se ha señalado, como un elemento que influyó en la mala performance de El Tejar, la falta de una adecuada profesionalización de una estructura empresarial que se había transformado en una corporación. Otra razón, vinculada con esta última, fue la escasa atención prestada a las particularidades de las formaciones socioespaciales brasileñas. 
Este concepto, acuñado por Milton Santos (Santos, 1977a, p. 97), hace referencia a las formas en las que se materializa un determinado modo de producción en un lugar en particular. Busca dar cuenta del modo en que las manifestaciones sociales, económicas y políticas transforman el espacio, y cómo el espacio condiciona la evolución global de los fenómenos.

Desde esta perspectiva, se entiende que las herencias materiales (naturales y sociales) y sociopolíticas presentes en el espacio son elementos centrales para comprender la emergencia o la presencia de determinado fenómeno. En el caso estudiado, esto se ve en el modo en que los fondos financieros debieron adaptarse a las "rugosidades" (Santos, 2009) presentes en las áreas de expansión de la frontera agrícola brasilera.

En cierta medida, la menor productividad se debió a la implementación de técnicas inadecuadas para las características de los suelos brasileros, menos fértiles, entre otras razones porque los técnicos argentinos que El Tejar instaló en Brasil no tenían una formación agronómica universitaria, sino práctica, adquirida durante su experiencia en la propia empresa:

El Tejar [...] venían de una región que no necesitaba fertilizante, cuando llega y tiene que invertir eso cambia toda la inversión; saber eso iba a repercutir en la visión de los inversores, y su propuesta había sido un crecimiento exponencial (Entrevista a proveedor de insumos, 2015; la traducción es propia).

Estos técnicos desconocían los calendarios adecuados para realizar la siembra en función de las características agronómicas y climáticas de los Cerrados, trasplantando sin más los calendarios utilizados en Argentina. En el municipio de Primavera do Leste, donde se instaló El Tejar, el momento más adecuado o "ventana óptima de siembra" es entre inicios de octubre y comienzos de noviembre. No hacer la siembra en esos momentos no solo implica acortar la duración de las etapas fenomenológicas y del ciclo del cultivo, sino que también tiene una marcada influencia en los rendimientos.

También por razones agronómicas, y por la inexistencia legal de "contratos accidentales", los contratos por el alquiler de la tierra debieron superar necesariamente el año o dos que se estilaba en Argentina. La menor fertilidad del suelo (de gran acidez y bajo tenor de arcilla) obligó a realizar estos contratos a más largo plazo, que llegaron a ser de 5 a 10 años, y a veces incluso más.

A esto se sumó, como ya fue destacado, la imposibilidad de encontrar prestadores de servicios aptos para realizar las tareas que El Tejar terceriza en contratistas en Argentina. La práctica de la tercerización de actividades data de inicios de la producción extensiva agrícola en ese país (Bialet Massé, 1986). Por eso, la empresa contaba allí con un mercado diversificado, con agentes con distintas capacidades económicas y tecnológicas, que le permitió dedicarse a la gestión de los activos de terceros.

A la hora de intentar replicar la práctica de la tercerización en Brasil, no se tuvo en cuenta que, en regiones como Mato Grosso, los productores realizan las labores con maquinaria propia y, además, no suelen recurrir a la venta de servicios como una estrategia de obtención de ingresos adicionales. En Primavera do Leste, donde se asentó El Tejar en Mato Grosso, gran parte de la población provenía de migraciones de colonos del Sur de Brasil (los llamados gaúchos), que "con la venta de 30 hectáreas en el sur podían comprar una propiedad de cientos e incluso miles” en los Cerrados (Wilkinson, Reydon, y Di Sabbato, 2012, p. 119).

El Tejar comenzó a alquilar las tierras a estos hacendados (fazendeiros), y desde 2007 también empezó a comprar tierras a aquellos que estaban endeudados (Wesz Junior, 2014, p. 117). Inclusive, algunos de los estos hacendados que poseían maquinarias (muchas veces obsoletas) comenzaron a venderle servicios a El Tejar.

En otras palabras, intentar trasplantar el modelo de negocios no solo planteaba el problema de cómo suplir la disponibilidad de maquinaria sino también el conocimiento agronómico que los contratistas aportan para la realización de las diferentes labores culturales en Argentina. Aquí se hace evidente, nuevamente, el peso de las formaciones socioespaciales específicas del territorio argentino en el surgimiento y en las posibilidades de éxito del "modelo en red".

Otra dificultad que se le presentó a la empresa para trasplantar el modelo de negocios argentino fue que la tercerización de las actividades principales de una empresa estaba prohibida por las leyes laborales brasileñas. 
Si bien no existían regulaciones específicas sobre la tercerización, desde 2003 el Tribunal Superior del Trabajo regulaba estas prácticas a través de la Súmula 331/TST, que era tomada como referencia en las instancias de justicia laboral.

El incumplimiento de estas regulaciones le valió a El Tejar problemas legales. En efecto, en 2010, la Federación Agropecuaria del estado de Mato Grosso (Federação da Agricultura e Pecuária de Mato Grosso, Famato), que representa a los "ruralistas" de ese estado, denunció a El Tejar ante el Ministerio Público del Trabajo (MPT) por prácticas de trabajo "análogas a la esclavitud" que tenían el objetivo de lograr una "ventaja indebida ante la competencia” (MPT, 2010; la traducción es propia).

Si bien por lo general se oponía a las leyes de protección laboral o ambiental, la Famato se valió de la legislación para denunciar posibles prácticas ilegales cometidas por El Tejar. Esto parece estar relacionado con el poder político de la familia Maggi en el estado -Blairo Maggi fue gobernador de Mato Grosso-, donde su Grupo Amaggi y el Grupo Bom Futuro, de su primo Eraí Maggi, son los principales competidores de El Tejar en cuanto grandes grupos nacionales productores de soja.

En síntesis, el intento de trasplantar el modelo de negocios sucumbió ante lo que puede denominarse, tomando la metáfora de Santos, una "revancha del territorio" (Santos, 1977b). Es decir, debió enfrentarse a inconvenientes vinculados con la existencia de un ambiente institucional diferente, de formaciones socioespaciales divergentes, y de una cultura también distinta a las que lo habían sustentado en Argentina.

Además, estas dificultades se vieron agudizadas por la creciente preeminencia de los objetivos financieros en la orientación de las decisiones económico-productivas. En efecto, el caso de El Tejar resulta paradigmático de las exigencias a las que se somete una empresa cuando grandes inversores se convierten en sus accionistas. Entre la primera y la segunda ronda de inversiones, en 2006 y 2011 respectivamente, fue aumentando, según exempleados, directores y gerentes de El Tejar consultados, la "presión por crecer" por parte de los inversores. Esa presión se tradujo en una acelerada expansión de la superficie trabajada, lo que incluyó, como ya señalamos, la compra de tierras.

En 2007-2008, El Tejar llegó a cultivar cerca de 600 mil hectáreas en los cuatro países donde producía, de las cuales más del $30 \%$ eran propias. En Argentina, se ubicaban poco menos de la mitad de los campos operados, 250 mil hectáreas, todasbajo alquiler. También intentó producir en Paraguay, y pretendía expandirse incluso más allá de la región.

Pese al rápido crecimiento de la empresa en pocos años, el objetivo inmediato de los fondos de private equity no pudo cumplirse. No solo porque los resultados productivos en Brasil no eran los mejores sino, ante todo, por la crisis financiera de 2008-2009, como consecuencia de la cual cayó el precio de las acciones en las bolsas de valores de todo el mundo, volviendo inviable el IPO que Altima Partners había programado hacer en la Bolsa de San Pablo (Bovespa) en esos días (El Cronista, 2009). Es importante destacar que, tal como se relevó en la entrevista a un alto directivo de la empresa, la intención inicial de estos fondos era adquirir parte del control societario de El Tejar con el objetivo de vender su participación dos años más tarde a través de la oferta pública de sus acciones. Es decir que, desde el inicio de su operación, los fondos tenían previsto el momento de su salida de la inversión.

Esta salida tampoco fue favorecida por la confluencia de la caída de precios internacionales de los commodities agrícolas y por la sequía de 2009. Además, la fuerte volatilidad de los principales activos financieros provocada por la debacle de ese año, en conjunción con el mantenimiento de la tendencia a la elevación de los precios de las tierras, aumentó todavía más el interés de los fondos financieros por la empresa.

En ese marco, El Tejar continuó invirtiendo en la compra de campos, particularmente en Brasil. Debido al precio relativamente bajo y la gran cantidad de tierras agrícolas, ese país se transformó en el principal destino de las inversiones de la empresa, y la empresa se convirtió definitivamente en un vehículo para el desembarco y canalización de inversiones financieras en tierras.

Luego del IPO fallido, en 2009, el fondo creado por Altima (Altima One Word Agricultural Fund, AOWAF) volvió a inyectar dinero en El Tejar, que a cambio debió entregar parte de las acciones que 
quedaban aún en manos de las familias fundadoras. En esta oportunidad, AOWAF recibió su mayor contribución de la International Finance Corporation (IFC), el brazo de inversiones en el sector privado del Grupo Banco Mundial (World Bank Group, WBG).

La IFC funciona como intermediaria en el mundo de las inversiones de tipo private equity en actividades agrícolas (Bergdolt y Mittal, 2012, p. 12), en particular en países "subdesarrollados" que buscan abrir su mercado de tierras a inversores externos. Esta entidad participa de las conferencias Global AgInvesting (HedgeCo.Net, 2014), uno de los mejores exponentes del papel desempeñado por las agencias gubernamentales y bancos de desarrollo en el actual fenómeno de land grabbing.

Para la IFC, la inversión en AOWAF fue la mayor de su historia hasta ese momento en el sector de los agronegocios, llegando a los US\$ 75 millones (Thilakasiri, 2011, p. 5). Gracias a estas inversiones, El Tejar consiguió sembrar 900 mil hectáreas, a cargo de 600 empleados directos. Ese año, 25 mil llegaron a ser las personas que trabajaron para la empresa "casi con exclusividad, aunque no pagaba sueldos sino que tenía contratos". El foco de la operación de El Tejar seguía siendo "gerenciar procesos" (FISOA, 2012, p. 124).

Este nuevo influjo de capital aportado por el IFC a través de Altima significó que estos grandes capitales financieros adquirieran una participación accionaria todavía mayor en El Tejar. Tanto la familia Alvarado como las de los primeros accionistas se vieron obligados a venderles sus acciones para recibir fondos "frescos" que les permitieran compensar las pérdidas generadas en el plano productivo.

A partir de esta nueva inversión, la presión por crecer no solo se intensificó, sino que, para lograr un mayor control sobre ese crecimiento, AOWAF impulsó la reestructuración de la línea directiva de El Tejar. Fueron los primeros pasos en el armado de un "gobierno corporativo" de la empresa: Alvarado, quien pocos meses después falleció, dejó su cargo como CEO para quedar como presidente o chairmain de la compañía; ${ }^{1}$ al mismo tiempo, ingresó al directorio un representante de Altima Partners. Estos cambios buscaban realizar los "ajustes" necesarios para asegurar a los inversores el retorno de su capital, generando una presión creciente sobre los trabajadores para aumentar las ganancias. De tal modo, en 2010, los inversores financieros controlaban más del $60 \%$ de la empresa, mientras que el resto pertenecía a las familias fundadoras y a otros accionistas minoritarios.

Gracias a las sucesivas capitalizaciones y a los préstamos tomados ante instituciones financieras internacionales por casi US\$ 800 millones, El Tejar había llegado a convertirse, por fin, en la empresa productora de granos más grande del mundo. Controlaba alrededor de 250 mil hectáreas en las regiones pampeana y chaqueña, en Argentina, otras 250 mil en Mato Grosso, Brasil, más de 150 mil en Uruguay (Oyhantçabal y Narbondo, 2011), y aproximadamente 30 mil hectáreas en Santa Cruz de la Sierra, en Bolivia. Es decir, alrededor de 800 mil hectáreas en el sur de Sudamérica.

En ese momento la estrategia empresarial volvió a cambiar porque las pérdidas económicas en la producción de commodities continuaron. Además, los ahora accionistas mayoritarios pretendían pagar los préstamos tomados conservando el retorno sobre el capital que habían aportado.

En paralelo, otro fondo de private equity estadounidense ingresó como inversor: Crestline Investors. Las familias fundadoras debieron vender su parte de las acciones, que para el momento se habían desvalorizado. Desde ese momento, El Tejar pasó a estar controlada enteramente por inversores institucionales: $54 \%$ de las acciones pertenecía a Altima Partners, 32 \% a Capital Group, 11 \% a Crestline Investors, y el resto a otros inversores minoritarios. Los nuevos dueños de la empresa tomaron, a partir de ese momento, decisiones que iban a cambiar drásticamente la estrategia y la estructura empresarial, como se verá en el apartado siguiente.

\section{DESINVERSIÓN Y CAMBIO DE ESTRATEgIA}

A mediados de 2011, El Tejar había llegado a ser el mayor productor de soja de Brasil, donde concentraba más del 60\% de sus actividades. El periódico Folha de São Paulo (Hennemann, 2011) anunció que ese año la empresa había cosechado un 17 \% más que Eraí Maggi Scheffer, del Grupo Bom Futuro, lo que superaba las 
670 mil toneladas de soja. Aun habiendo comprado tierras desde 2006, El Tejar seguía arrendando tres veces la cantidad que tenía en propiedad a nivel regional. En ese momento, se buscó, como en 2008, la venta de la compañía en Brasil a través de la Bolsa de Valores de Nueva York por US\$300 millones (Caligaris, 2017, p. 479), o incluso volver a intentar en la de San Pablo.

Sin embargo, como vimos, el nivel de endeudamiento de la empresa, producto de varios años de malas decisiones agronómicas y de gestión, no lo permitió. La producción había crecido a fuerza del aumento de la cantidad de hectáreas controladas, pese a una muy baja productividad. En la campaña 2012-2013, el rinde promedio logrado por la empresa fue de $44 / 45$ bolsas de soja por hectárea, es decir, un $20 \%$ inferior a la del estado de Mato Grosso (Entrevista a alto directivo de El Tejar, 2014), y de 80 bolsas de maíz (Ondei, 2015, p. 50).

En cuanto a la situación en Argentina, desde 2009 los números eran negativos y, como en el caso Los Grobo, "el último tiempo el contratista fue el medio de ajuste que tuvieron ellos" (Entrevista a PyME de Saladillo, 2014). A nivel regional el negocio agrícola no daba ganancias: "La compañía perdió, entre Brasil y otros países, algunas centenas de millones de dólares" (Entrevista a alto directivo de El Tejar, 2014; la traducción es propia).

El único negocio que arrojó resultados positivos fue el de real estate. En estas condiciones, en 2012 se produjo una nueva ronda de capitalización, y los fondos de private equity que manejan la empresa emprendieron una nueva reestructuración, más radical que la anterior, de 2010. En 2013, se sustituyó al CEO de la empresa y se incorporó a un profesional especialista en reestructuraciones empresariales, para llevar a cabo esta tarea. Esta persona había reestructurado alrededor de 10 empresas (de telecomunicaciones, salud, educación, producción azucarera); en una entrevista aclaraba:

yo no entiendo nada de agricultura, si me muestran una planta de soja y una de maíz no voy a saber cuál es cuál, sino que mi experiencia es en reestructuraciones (...) yo solo hago la recuperación de la empresa. Mis proyectos son de un año y medio más o menos (Entrevista a alto directivo de El Tejar, 2014; la traducción es propia).

La reestructuración de El Tejar precisó de un diagnóstico previo y un plan de acción que incluyó la salida de la inversiónde la mayoría de las operaciones de la empresa y la venta de activos. Con respecto a Argentina, los entrevistados explican que "era un combo perfecto de desfinanciación, costos altos, costo de tierra alto y precios de los commodities bajos" (Entrevista a M, ex empleado de El Tejar, 2014). Así fue que, luego de cerrar la empresa en Argentina (en 2014 se vendió por US\$ 50 millones la unidad más grande que tenía en el país), se procedió a la salida de la inversión en Uruguay. Ese año, El Tejar vendió por US\$170 millones su operación en Uruguay a la empresa agrícola británica Union Group a través de su filial uruguaya Union Agriculture Group (UAG). Se trataba de 67 mil hectáreas y del negocio de feedlot, si bien El Tejar conservó Semillas Latitud, de la cual participa junto a la empresa Solaris (El Cronista, 2014).

La intención fue concentrarse en Brasil, pero reduciendo el área arrendada a 84 mil hectáreas propias, y arrendando una cantidad similar. Además, se adaptaron las técnicas productivas a las tierras del Cerrado. También se puso en marcha una estrategia de compra de maquinaria propia, tal como se hacía en Uruguay desde un lustro atrás.

Esta estrategia buscaba subsanar uno de los problemas principales que El Tejar había enfrentado en términos productivos: la escasez y antigüedad de la maquinaria de aquellos fazendeiros a quienes El Tejar había arrendado tierras e integrado a su esquema productivo como prestadores de servicios. Sin embargo, se siguió manteniendo una porción mínima de tercerización, para tener cierta flexibilidad.

En cuanto a las tierras propias, El Tejar debió detener las operaciones de compra por las restricciones impuestas, en 2010, a la adquisición de tierras por extranjeros o por empresas brasileñas controladas por capital extranjero. Sin embargo, de querer volver a adquirir tierras, la empresa puede asociarse con otras empresas locales existentes o creadas ad hoc para ello. En cuanto a las tierras adquiridas con anterioridad, no le generan conflictos legales. 
Recientemente, El Tejar sufrió denuncias en Brasil por adquisición ilegal de inmuebles rurales a través de arrendamientos ficticios, hipotecas fiduciarias (préstamos) millonarias, y contratos de gaveta, que consisten en "la maniobra de comprar las tierras y no efectuar formalmente la transferencia de propiedad" a través de pre-contratos de compra-venta [contratos de promessa de compra e venda] que no son registrados legalmente (Pacheco, 2015).

En el siguiente gráfico se muestra la evolución de las tierras controladas por El Tejar en el período analizado. Dado que la información al respecto es relativamente escasa o poco fiable, no se distingue aquí entre la propiedad y el arrendamiento, ni entre los diferentes países del Mercosur donde se expandió. No obstante, el gráfico permite observar el vínculo entre el acaparamiento de tierras y el ingreso de capitales de riesgo en El Tejar:

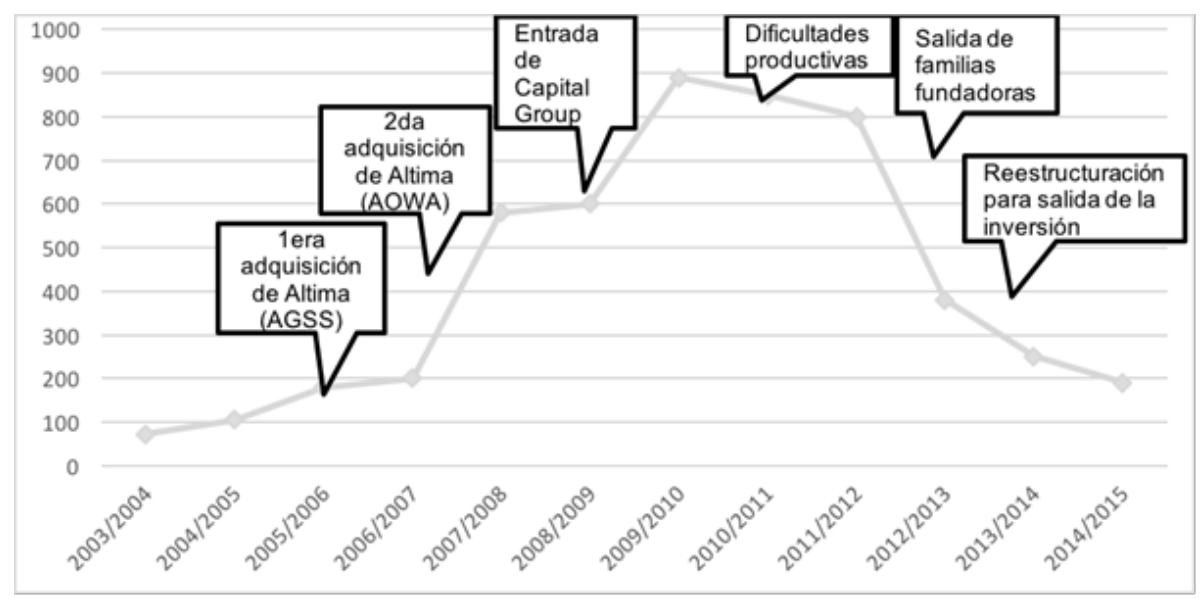

FIGURA 1

Miles de hectáreas controladas por El Tejar en el Mercosur (2003/04-2014/15)

Fuente: elaboración propia a partir de documentos de la empresa, noticias periodísticas, entrevistas, informes, estudios de caso. Las 300 mil hectáreas supuestamente adquiridas a través de contratos

de gaveta no fueron tenidas en cuenta, ya que se trata de un cálculo realizado a partir de denuncias.

Mientras tanto, el objetivo siguió siendo preparar el momento del exit final, en el que los fondos pretenden liquidar la empresa y hacerse de la ganancia generada por la reestructuración. Para ello procedieron a estabilizarla y así convertirla en una "novia deseada", es decir, atractiva para ser vendida en la Bolsa.

Esta reestructuración también responde a que los gestores de los fondos de inversión necesitaban "salvar la compañía" porque habían invertido mucho en ella, y tenían "una obligación fiduciaria ante sus inversores de recuperar parte de lo invertido". Sin embargo, todos "van a perder un buen dinero (...) incluso si la compañía se valoriza (...) seguramente no van a recuperar el capital invertido" (Entrevista a alto directivo de El Tejar, 2014; la traducción es propia).

En Mato Grosso solo continuaron bajo el esquema asociativo 4 grandes haciendas. Los resultados de los cambios agronómicos y del manejo del personal realizados en el proceso de reestructuración empresarial fueron drásticos. En la campaña 2013/14 se aumentó la productividad promedio en las cosechas de soja y maíz (17 \% y 40 \% respectivamente en comparación con la campaña anterior (Ondei, 2015, p. 50). Según un alto directivo de El Tejar, en 2014 la productividad ya estaba por encima de la media de Mato Grosso (Entrevista a alto directivo de El Tejar, 2015).

De todas formas, las dificultades financieras de la empresa siguieron siendo evidentes, y se expresan en su morosidad. Fuentes periodísticas aseguran que la empresa incurre en retrasos en el pago a los grandes propietarios a los que arrienda sus tierras o con quienes produce en sociedad. Por lo demás, muchos de estos parceiros (socios) rescindieron sus contratos con El Tejar, ya que consideran que "canibalizan" sus propiedades al no invertir en la estructura física de las haciendas que arrienda (Brasil Notícia, 2015). 


\section{CONCLUSIONES: FINANCIARIZACIÓN Y ACAPARAMIENTO DE TIERRAS Y DE LA PRODUCCIÓN}

Este estudio dio cuenta de la trayectoria de la megaempresa El Tejar desde una perspectiva multiescalar. Permitió conectar a) procesos nacionales como la emergencia del llamado "modelo en red", pasando por b) procesos regionales como la expansión de la frontera agrícola en el Mercosur, hasta c) fenómenos mundiales como el acaparamiento de tierras y de recursos a gran escala por las grandes corporaciones agropecuarias, así como sus articulaciones con el capital financiero internacional.

En cuanto al último punto, se mostró, por un lado, el modo en que las sucesivas adquisiciones realizadas por fondos de private equity entre 2006 y 2011 fueron modificando las estrategias empresariales de El Tejar. Estos inversores pretendían obtener un retorno sobre su inversión en pocos años -entre la entrada del primer fondo en 2006 y el intento trunco de apertura de capital de 2008- por lo que impusieron a la empresa una fuerte presión por crecer. Por ello, constituye un ejemplo de uno de los efectos más corrientes de la financiarización: el creciente control sobre las lógicas de acumulación que ejercen los inversores institucionales a medida que las rondas de inversión se suceden.

Esta presión por crecer implicó la ampliación del área productiva en aproximadamente un $200 \%$ en ese período, desde cerca de 200 mil a unas casi 600 mil hectáreas, principalmente en Brasil y en Bolivia. Dado que en esos años la capitalización provocada por la elevación de los precios de los commodities en el mercado internacional atizó el deseo de los inversores de adquirir y conservar tierras, en Brasil, El Tejar terminó comprando o arrendando tierras marginales a precios elevados.

Es decir que, por otro lado, el caso de estudio aquí analizado muestra en detalle la presencia en territorio brasilero de la megaempresa de origen argentino El Tejar como una expresión del fenómeno mundial de acaparamiento de tierras y de la producción agrícola por parte de grandes fondos controlados por firmas de private equity. Asimismo, demuestra que, pese al enorme poder adquirido por las instituciones financieras en la economía mundial, en el agro, la capacidad de imponer sus lógicas financieras y sus exigencias de rentabilidad sobre las empresas en las que invierten no deja de estar influida por las formaciones socioespaciales específicas de cada territorio.

Las herencias técnico-productivas y sociopolíticas de las formaciones socioespaciales brasileñas restringieron las formas de operar de El Tejar. La mala lectura de estas especificidades socioespaciales, así como el gran endeudamiento en el que incurrió la empresa para llegar a ser la más grande del mundo, tuvieron como consecuencia la profunda reestructuración de sus operaciones desde 2012. Esto implicó la venta de todas las operaciones en Argentina y Uruguay, y gran parte de las de Bolivia y Brasil, así como cambios de personal y de cargos directivos. La elección de un nuevo director ejecutivo proveniente del mundo de las finanzas y experto en reestructuraciones empresariales da cuenta de una estrategia enfocada en preparar la salida total de la inversión, es decir, la venta de la empresa.

Pese a la importancia adquirida por las firmas de private equity en el capitalismo contemporáneo, las consecuencias de sus acciones siguen siendo en gran medida inciertas. Esto se debe a la escasez de información respecto de las acciones de estas firmas, exceptuadas de la obligación de dar a conocer información que recae sobre las empresas públicas, lo que las convierte en uno de los actores financieros menos estudiados y regulados.

A su vez, esto conlleva una dificultad metodológica suplementaria, que supone identificar el entramado financiero por detrás de las corporaciones y, más aún, conocer las prácticas concretas de los actores financieros y el peso que tienen en el seno de esas corporaciones. En este trabajo se mostraron los efectos que conlleva el accionar habitual de las firmas de private equity.

La constante búsqueda de un incremento de la competitividad lleva a procesos contradictorios de destrucción creativa de la empresa (Schumpeter, Stiglitz, Díaz García, y Limeres, 2015), pero también del espacio (D. Harvey, 2013; D. A. Harvey, 1990). Esto último implica la necesidad del capital de incorporar y reestructurar el espacio de manera continua para dar lugar a formas más eficaces de acumulación. En el caso 
de las empresas vinculadas a la agricultura moderna, esto se hace evidente en la necesidad de crecer en escala y de aumentar la productividad, lo que implica una mayor explotación de la naturaleza y del trabajo. El doble proceso de destrucción creativa - de la empresa y del espacio- se ve exacerbado por la financiarización, ya que las exigencias del poder accionarial lo intensifican.

En el caso estudiado, las exigencias de rápido crecimiento, alto retorno sobre el capital invertido, y liquidación de la empresa (u operaciones de la empresa) en un corto plazo tuvieron consecuencias para los trabajadores y el territorio. En Argentina, los contratistas se convirtieron en el "medio de ajuste" del "modelo en red" cuando la rentabilidad bajó, y las tierras alquiladas fueron sometidas a una sobreexplotación. En Brasil, además del "dumping social" y del aumento de la explotación de la fuerza de trabajo para alcanzar los estándares de los inversores a través de la tercerización ilegal de las actividades y de jornadas exhaustivas de trabajo, El Tejar recurrió -según la información periodística citada (Pacheco, 2015) - a artilugios legales para intentar franquear las leyes que limitan la compra de tierras por parte de extranjeros, y de este modo responder a las exigencias de los inversores.

\section{ReFERENCIAS}

Aglietta, M., y Rebérioux, A. (2004). Dérives du capitalisme financier. París: Albin Michel.

Altman, R. C. (2009). The great crash, 2008: a geopolitical setback for the West. Foreign Affairs, 2-14. Recuperado de http://www.jstor.org.

Arrighi, G. (2010). The long twentieth century: money, power and the origins of our times (nueva edición aumentada). Londres: Verso.

Artopoulos, A. (2015). Desarrollo Informacional en América Latina. Casos de Pioneros de Buenos Aires (1980-2014) (Tesis de Doctorado). Universitat Oberta de Catalunya, Barcelona.

Bell, D. E., y Scott, C. (2010). Los Grobo: ¿El futuro de la agricultura? Cambridge MA: Harvard Business School. Recuperado de http://www.losgrobo.com.ar.

Bergdolt, C., y Mittal, A. (2012). Betting on World Agriculture. US private equity managers eye agricultural returns. (M. Moore, Ed.). The Oakland Institute. Recuperado a partir de https://www.oaklandinstitute.org.

Bernardes, J. A., y da Silva, A. A. (1997). Notas sobre a dinâmica do capital no complexo da soja. Anuário do Instituto de Geociências, 20, 27-37. Recuperado de http://www.ppegeo.igc.usp.br.

Bernardes, J. A., Frederico, S., Gras, C., Hernández, V., y Maldonado, G. I. (Eds.). (2017). Globalização do agronegócio e landgrabbing. A atuação das megaempresas argentinas no Brasil. Río de Janeiro: Lamparina.

Bialet Massé, J. (1986). Informe sobre el estado de la clase obrera en 1904 (Vol. 2). Madrid: Hyspamérica.

Biavaschi, M. B., y Teixeira, M. O. T. (2015). A terceirização e seu dinâmico processo de regulamentação no Brasil: limites e possibilidades. Revista da ABET. Recuperado de http://periodicos.ufpb.br.

Bloomberg. (2017). Company Overview of El Tejar Ltd. Recuperado de www.bloomberg.com

Boyer, R. (1998). Evolution des modèles productifs et hybridation: Géographie, histoire et théorie (Vol. 9804). CEPREMAP. Recuperado de http://www.cepremap.fr.

Burch, D., y Lawrence, G. (2005). Supermarket Own Brands, Supply Chains and the Transformation of Agri-food System. International Journal of Sociology of Agriculture and Food, 13(1), 1-18.

Burch, D., y Lawrence, G. (2009). Towards a third food regime: behind the transformation. Agriculture and Human Values, 26(4), 267-279. doi.org/10.1007/s10460-009-9219-4

Caligaris, G. (2017). Las grandes empresas agropecuarias en Argentina: los casos de Cresud y El Tejar. Cuadernos de Economia, 36(71), 469-488. Recuperado de http://www.revistas.unal.edu.co.

Chesnais, F. (1996). Mondialisation du capital \& régime d'accumulation à dominante financière. Agone. Philosophie, Critique \& Littérature, 16, 15-39.

Chesnais, F. (2004). La finance mondialisée. Racines sociales et politiques, configuration, conséquences. La Découverte. 
Clarke, T. (12 de junio 2015). The Dot-Com Crash of 2000-2002. Money Morning. Recuperado de http:// moneymorning.com.

Cochrane, J. H. (2005). The risk and return of venture capital. Journal of Financial Economics, 75(1), 3-52. doi.org/10.1016/j.jfineco.2004.03.006

Cotula, L. (2012). The international political economy of the global land rush: A critical appraisal of trends, scale, geography and drivers. Journal of Peasant Studies, 39(3-4), 649-680. doi.org/10.1080/03066150.2012.674940

Daniel, S. (2011). The Role of the international finance corporation in promoting agricultural investment and large-scale land acquisitions (pp. 1-23). Presentado en International Conference on Global Land Grabbing, Land Deals Politics Initiative (LDPI) / Journal of Peasant Studies / Future Agricultures Consortium at the Institute of Development Studies, University of Sussex. Recuperado de http://www.iss.nl.

Ducastel, A., y Anseeuw, W. (2011). Le «\#production grabbing\#» et la transnationalisation de l'agriculture (sud-)africaine. Transcontinentales. La ruée vers la terre, 10/11. Recuperado de http://transcontinentales.revu es.org.

Fondo de inversión agrícola argentino pospone su salida a bolsa en Brasil. (21 de enero de 2009). El Cronista.

La argentina El Tejar vendió su negocio en Uruguay por US\$ 170 millones. (25 de febrero de 2014). El Cronista.

El Tejar. (2009). El Tejar. Un sueño compartido (4ta.). El Tejar Ltd.

Embrapa Cerrados. (27 de septiembre de 2010). Plantio da soja na época certa. Agrolink.

EMPEA. (2015). Global limited Partners survey. Investors' views of private equity in emerging markets. Washington, D.C: Emerging Markets Private Equity Association. Recuperado de www.empea.org.

Epstein, G. (2001). Financialization, rentier interests, and central bank policy. Presentado en PERI Conference on Financialization of the World Economy, University of Massachusetts, Amherst. Recuperado de http://citesee rx.ist.psu.edu.

Borras Jr., S, Kay, C., Gómez, S., Wilkinson, J. (2012). Land grabbing and Global Capitalist Accumulation: Key Features in Latin America. Canadian Journal of Development Studies, 33(4), 402-416.

Fairbairn, M. (2014). "Like gold with yield": evolving intersections between farmland and finance. The Journal of Peasant Studies, 41(5), 777-795. doi.org/10.1080/03066150.2013.873977

French, S., Leyshon, A., y Wainwright, T. (2011). Financializing space, spacing financialization. Progress in Human Geography, 35(6), 798-819. https://doi.org/10.1177/0309132510396749

FISOA, (Fundación para la Integración Social Oscar Alvarado) (Ed.). (2012). Oscar Alvarado: emprender con valores. Buenos Aires: Sudamericana.

Goldfarb, Y. (2013). Financeirização, poder corporativo e expansão da soja no estabelecimento do regime alimentar corporativo no Brasil e na Argentina: o caso da Cargill. Programa de Pós-graduação em Geografia Humana, Faculdade de Filosofia Letras e Ciências Humanas, Universidade de São Paulo, São Paulo, Brasil.

GRAIN (2008). Seized: The 2008 land grab for food and financial security. Grain Briefing. Recuperado de www.grain.org.

Gras, C. (2013). Agronegocios en el Cono Sur. Actores sociales, desigualdades y entrelazamientos transregionales (Working Paper Series No. 50). Berlín: desiguALdades.net International Research Network on Interdependent Inequalities in Latin America. Recuperado de http://www.diss.fu-berlin.de.

Gras, C., y Göbel, B. (2014). Agronegocio y desigualdades socioambientales: la soja en Argentina, Brasil y Uruguay. En B. Göbel, M. E. Góngora Mera, y A. Ulloa (Eds.),Desigualdadessocioambientales en América Latina (1era edición, pp. 211-254). Berlin, Alemania / Bogotá, Colombia: Ibero-Amerikanisches Institut, Preussischer Kulturbesitz / Universidad Nacional de Colombia, Facultad de Ciencias Humanas, Grupo Cultura y Ambiente.

Gras, C., y Hernández, V. (2016). Hegemony, Technological Innovation and Corporate Identities: 50 Years of Agricultural Revolutions in Argentina. Journal of Agrarian Change. doi.org/10.1111/joac.12162

Gras, C., y Sosa Varrotti, A. P. (2013). El modelo de negocios de las principales megaempresas agropecuarias. En C. Gras y V. Hernández (Eds.), El agro como negocio: producción, sociedad y territorios en la globalización. Buenos Aires: Biblos. 
Harvey, D. (2013). El enigma del capital y las crisis del capitalismo. Madrid: Akal.

Harvey, D. A. (1990). Los limites del capitalismo y la teoría marxista. México: FCE.

Hennemann, G. (21 de agosto de 2011). Novo rei da soja no Brasil é argentino. Folha de S. Paulo. Recuperado de h ttp://www1.folha.uol.com.br.

Honan, M., y Leckart, S. (17 de febrero de 2010). 10 years after: a look at the dotcom boom and bust. Wired. Recuperado de www.wired.com.

Jezur, E., y Dias Kraemer, M. A. (2016). A terceirizaçâo e o projeto de Lei N. 4330/2004: uma análise comparativa da legislaçâo trabalhista. Revista Direito e Sociedade: reflexôes Contemporâneas/Faculdades Integradas Machado de Assis - Santa Rosa, 7(2).

El Tejar siempre dispuso hacer plata con la gente y no a pesar de la gente. (25 de junio de 2003). La Mañana.

Lawrence, G., Sippel, S. R., y Burch, D. (2015). The financialisation of food and farming. En G. M. Robinson y D. A. Carson (Eds.), Handbook on the Globalisation of Agriculture (pp. 309-327). Edward Elgar. Recuperado de htt p://books.google.com.

Masters, M. (2008). Are Index Investors Driving Up Commodity Prices? Journal of Indexes, 11(6). Recuperado de h ttp://www.etf.com.

McMichael, P. (2012). The land grab and corporate food regime restructuring. The Journal of Peasant Studies, 39(34), 681-701. doi.org/10.1080/03066150.2012.661369.

Moreno, M. (2017). Los actores sociales frente a los cambios en el agro pampeano: análisis de empresarios agropecuarios en tensión entre lógicas productivas y sociales diferentes en tres partidos de la provincia de Buenos Aires. Revista Huellas, 21(2), Instituto de Geografía, EdUNLPam: Santa Rosa. Recuperado a partir de: http:// cerac.unlpam.edu.ar.

MPT. (22 de abril de 2010). Empresa argentina instalada em Mato Grosso é investigada pelo MPT devido a fraudes trabalhistas. Jusbrasil.

Murmis, M. (1998). El agro argentino: algunos problemas para su análisis. En N. Giarracca y S. Cloquell (Eds.), Las agriculturas del MERCOSUR: el papel de los actores sociales (1a. ed, pp. 205-248). Buenos Aires: Editorial La Colmena\#: CLACSO.

Nanda, R., Samila, S., y Sorenson, O. (2017). The Persistent Effect of Initial Success: Evidence from Venture Capital. Recuperado de papers.ssrn.com.

Nasdaq. (2017). Vocabulario Bolsa. La Semana del Nasdaq. Recuperado de nasdaq.wordpress.com.

Nichols, J., y Ordoñez, H. (2003). Agronegocios, escenarios turbulentos, economias emergentes, Argentina. Caso Los Grobo (p. 34). Universidad de Buenos Aires / Texas A \& M University. Recuperado de http://www.losgrobo.com.ar.

Ondei, V. (2015). Arrumando a casa. Dinheiro Rural (pp. 48-50).

Oyhantçabal, G., y Narbondo, I. (2011). Radiografia del agronegocio sojero. Descripción de los principales actores y de los impactos socio-económicos en Uruguay. Montevideo, Uruguay: REDES-AT/Uruguay Sustentable. Recuperado de http://www.academia.edu.

Pacheco, A. P. (28 de mayo de 2015). Grupo El Tejar deve ser investigado por operações ilegais de compra de terras em Mato Grosso. Centro-Oeste Popular Online.

Palermo, A. (10 de julio de 2004). Con filosofía propia. La Nación.

Pierrakis, Y. (2010). Venture capital: now and after the Dotcom crash. Nesta. Recuperado de http://eprints.kingston .ac.uk.

Plihon, D. (2009). Le nouveau capitalisme (3era ed.). París: La Découverte.

Revolvy. (2017). Netherlands Development Finance Company FMO.

Santos, M. (1977a). Sociedade e espaço: a formação social como teoria e como método. Boletim Paulista de Geografia, 54 (número especial), 81-100.

Santos, M. (1977b, agosto 3). A revanche do território. Folha de S. Paulo. Recuperado de http://wwwl.folha.uol.co m.br. 
Santos, M. (2009). A natureza do espaço: técnica e tempo, razão e emoção (4. ed., 5. reimpr.). São Paulo, SP: Edusp, Ed. da Univ. de São Paulo.

Sassen, S. (2010). A Savage Sorting of Winners and Losers: Contemporary Versions of Primitive Accumulation. Globalizations, 7(1-2), 23-50. doi.org/10.1080/14747731003593091

Sauer, S. (2010). Terra e modernidade: a reinvenção do campo brasileiro. São Paulo: Expressão Popular.

Schumpeter, J. A., Stiglitz, J. E., Díaz García, J., y Limeres, A. (2015). Capitalismo, socialismo y democracia. Barcelona: Página Indómita.

Singh, K. (2008). Taking It Private. The global consequences of private equity (No. Briefing 37). The Corner House. Recuperado de http://www.thecornerhouse.org.uk.

Sosa, A. P. (2017). El papel de las megaempresas agropecuarias en la financiarización del régimen alimentario global. Los casos del Grupo Los Grobo y El Tejar en Argentina y en Brasil (1996-2015) (Tesis de Doctorado). Universidad de Buenos Aires / Université de Toulouse 2 - Jean Jaurès, Buenos Aires / Toulouse.

Sull, D. N. (2005). No Exit: The Failure of Bottom-up Strategic Processes and the Role of Top-down Disinvestment. En J. L. Bower y C. G. Gilbert (Eds.), From resource allocation to strategy (pp. 155-175). Oxford: Oxford University Press.

The Economist. (2004, noviembre 25). The new kings of capitalism. The Economist. Recuperado de http://www.ec onomist.com.

Thilakasiri, S. (2011). Risky business: intermediary lending and development finance. Oxfam GB.

Toledo López, V. (2017). Territorio y acumulación: Sobre megaempresas y lógica del agronegocio en el noroeste argentino. Trabajo y sociedad, 29, 177-193. Recuperado en 18 de julio de 2018, de http://www.scielo.org.ar

Wesz Junior, V. J. (2014). O mercado da soja e as relaçôes de troca entre produtores rurais e empresas no Sudeste de Mato Grosso (Brasil). Instituto de Ciências Humanas e Sociais, Universidade Federal Rural do Rio de Janeiro. Recuperado de http://www.academia.edu.

Wilkinson, J., Reydon, B., y Di Sabbato, A. (2012). El caso de Brasil. En FAO, F. Soto Baquero y S. Gómez (Eds.), Dinámicas del mercado de la tierra en América Latina y el Caribe concentración y extranjerización. (pp. 105-144). FAO. Recuperado a partir de http://public.eblib.com.

Wolford, W., Borras Jr., S. M., Hall, R., Scoones, I., y White, B. (Eds.). (2013). Governing Global Land Deals: the Role of the State in the Rush for Land. Chichester, West Sussex, United Kingdom: Wiley Blackwell.

\section{Notas}

1. Aunque ambas funciones suelen estar concentradas en la misma persona, el presidente es el fundador de la compañía, y aunque participa de la toma de decisiones, no alcanza el nivel de responsabilidad del CEO, a quien responden el resto de los ejecutivos. 